\title{
Las nuevas ciencias de la vida
}

\section{Francisco Gutiérrez*}

Resumen. Siguiendo parcialmente el pensamiento de Hugo Assmann, quien plantea las preguntas basales de cómo educar y cómo aprender, se postula que se aprende durante toda la vida y mediante todas las formas de vida, coincidiendo ello con la facultad de los seres vivos de la autoorganización. Aprender resulta así un proceso donde coinciden los procesos vitales con los procesos de conocimiento. Surge de ello una biopedagogía que, asentada en el placer de aprender, está en condiciones de reencantar la educación. Para ilustrar las implicancias pedagógicas de este enfoque, se presentan los testimonios de cuatro vivencias de aprendizaje.

Palabras clave: ciencias de la vida, placer, experiencias de aprendizaje

\section{The new sciences of life}

Abstract. Following partly the thought of Hugo Assmann, who raises the baseline questions on how to educate and how to learn, it is postulated that one learns throughout the whole life and through all forms of life, coinciding with the power of living beings for self-organization. Learning becomes thus a process where life processes and knowledge processes coincide. It rises from this a biopedagogy that, based on the joy of learning, is capable of re-enchanting education. To illustrate the pedagogical implications of this approach, testimonies of four learning experiences are offered.

Key words: sciences of life, joy of learning, learning experiences

\section{As novas ciencias da vida}

Resumo: seguindo em parte o pensamento de Hugo Assmann, que levanta as questões de base e aprender a educar, postula-se que se aprende ao longo da vida e através de todas as formas de vida, coincidindo com o poder das coisas vivas do auto-organização. A aprendizagem é, portanto, um processo onde os processos vitais coincidiram com os processos de conhecimento. Surge esta biopedagogía que, com base na alegria de aprender, é capaz de re- encantar a educação. Para ilustrar as implicações pedagógicas dessa abordagem apresenta os testemunhos de quatro experiências de aprendizagem. aprendizagem

Palavras-chave: ciencias da vida, alegria de aprender, experiências de

Recibido: 25.02.2010

Aceptado: 17.03.2010

$* * *$

*U. de La Salle, San José, Costa Rica. Email: chifladuramundial@yahoo.com 


\section{Las nuevas ciencias de la Vida fundamento de la complejidad de la Educación}

Hugo Assmann es uno de los autores que con mayor cariño, inquietud y pasión ha investigado, sistematizado y promovido las nuevas ciencias de la Vida como fundamento de la complejidad. Desde el inicio de su libro "Reencantar a educaçao rumo a sociedade aprendente” (Ed. Vozes), plantea dos preguntas fundamentales: ¿Cómo educar y cómo aprender? Cuestionamientos que en esta sociedad del conocimiento pleno, conllevan respuestas radicalmente nuevas dado que el aprendizaje, desde la biopedagogía, es la propiedad emergente de la autoorganización de la vida. Aprender no puede reducirse, ni mucho menos, a la apropiación de los saberes acumulados por la humanidad. Se aprende durante toda la vida y mediante todas las formas de vida. Por eso los procesos cognitivos y procesos vitales son coincidentes, en y con la autoorganización, la complejidad, la creación, y la permanente conectividad de todos con todos, en todas las fases y momentos del proceso evolutivo. Aprender es por tanto un proceso biológico: "todo ser, pero principalmente los seres vivos, para existir y para vivir, tienen que flexibilizarse, adaptarse, reestructurarse, interactuar, crear y coevolucionar; tienen que convertirse en seres que aprenden; es decir, en sujetos aprendientes; en caso contrario, mueren”. (Leonardo Boff, en la Introducción al libro Reencantar la Educación)

Así es el proceso de vida de los seres aprendientes como lo expresa Hugo Assmann con meridiana claridad: "las ciencias de la vida están demostrando que la vida es básicamente una persistencia de procesos de aprendizaje por lo que los procesos vitales y los procesos de conocimiento son, en el fondo, la misma cosa”. Ambos procesos, “descubren su lugar de encuentro, marcado desde siempre, en el centro de lo que constituye la vida, es decir, en el proceso de autoorganización tanto desde el plano biofísico, como desde el plano social. La vida quiere seguir siendo vida. Se gusta y se ama, y en consecuencia anhela ampliarse en más vida. Vale la pena recalcar, como lo hace Hugo Assmann, que la vida (y por tanto el aprendizaje) se da siempre en el placer, en el gozo, incluso en la ternura. Precisamente ese es el título del libro en su edición en español: “Placer y Ternura en la Educación” (Ed. Nancea S.A).

Desde la biopedagogía el placer es una de las características básicas del aprendizaje. El conocimiento sólo emerge en su dimensión vitalizadora cuando tiene algún tipo de vinculación con el placer. Por eso se requiere una conversión sensorial para volver a dar significado a la vida.

Y para remover las fronteras dentro de las cuales fue aprisionado, en Occidente, el sistema educativo, la biopedagogía pone de manifiesto que el gozo es una de las claves pedagógicas inherentes a la nueva educación. En consecuencia: a) El arte supremo del maestro o maestra consistirá en despertar e incrementar el gozo de la expresión creativa y del conocimiento. b) El propósito fundamental de la educación deberá ser el de crear, recrear y promover espacios de aprendizaje agradable y satisfactorios; sólo 
en espacio en agradables, satisfactorios y placenteros pueden darse procesos de aprendizaje.

Hugo Assmann insiste reiteradamente en el placer de aprender como una de las tesis básicas para reencantar la educación. En uno de sus últimos libros "Curiosidad y placer de aprender", lo plantea como punto esencial: "La necesidad de que las y los educandos puedan aprender con alegría y curiosidad, en ambientes en donde se mantenga viva su sed de conocimiento y en donde reine una atmósfera donde no haya cabida para el miedo, ni para el temor, porque la curiosidad como comportamiento lúdico, agradable, provocador, determina el proceso de aprendizaje. Citando a Paulo Freire, contrapone la curiosidad provocadora a la actitud bancaria de la docencia acrítica y castradora. La curiosidad ligada, al tan difícil como placentero acto de aprender, consiste en la posibilidad de expresión libre y placentera porque "cuanto más metódicamente riguroso me vuelvo en mi búsqueda, tanto más alegre y esperanzado me siento. La alegría no llega solo por el encuentro de lo hallado, sino que forma parte del proceso de búsqueda. Enseñar y aprender, cita textualmente a Paulo Freire, "no pueden darse fuera de la búsqueda y consecuentemente fuera de la belleza y la alegría que conlleva la búsqueda”.

En este orden de ideas, la biopedagogía concibe el aprendizaje como la propiedad que tienen todos los seres vivos para autoorganizar la vida. El aprendizaje como un proceso de autoorganización de la vida, obedece a los mismos procesos que sustenta el paradigma emergente: autoorganización, incertidumbre y sostenibilidad. Veamos: el proceso de vivir es un proceso de cognición y el conocer es uno de los elementos esenciales que hace posible la autoconstrucción de los seres vivos.

Humberto Maturana y Francisco Varela llaman a este proceso "autopoiesis”. El significado etimológico clarifica el nuevo concepto: auto significa "sí mismo" y se refiere a la autonomía de los sistemas a autoorganizarse; "Poiésis” que tiene la misma raíz griega que poesía, significa creación, que por su misma esencia se da siempre en el placer, el gozo.

No concebimos una creación no poética. Por lo que autopoiésis significa creación de uno mismo en el placer inherente al ser siendo, al ser creándose. Por eso podemos afirmar que el aprender da origen a estados imprevisibles en razón de que el aprender no es almacenar conocimiento sino el de integrar la información que recibimos, al proceso de autoconstrucción personal. El aprendizaje que responde a la autoorganización de la información es necesariamente dinámico, flexible, vivo y consecuentemente holista y complejo.

Por lo expuesto, se comprenderá que estos estados imprevisibles, como resultado del aprendizaje, nos obligan a relativizar los contenidos y la docencia y en especial la didáctica. Esta dimensión del aprendizaje nos obliga a pasar de lo pre-establecido, pre-configurado, ordenado y estructurado a nuevas configuraciones dado que, los conocimientos no preexisten 
sino que el conocimiento lo crea cada persona que autoorganiza la información. Así lo sistematiza Hugo Assmann: "El conocimiento se construye, por medio de una red de interacciones neuronales extremadamente complejas y dinámicas, es decir, que el aprendizaje significativo tiene que ver siempre con el proceso creativo del ser vivo que se autoorganiza y se autoconstruye.

Varela habla de la enacción (to enact) como ese hacer emerger nuevas estructuras interactivas y dinámicas y complejas. Ya hemos señalado que son precisamente las experiencias de aprendizaje, como formas válidas y posibles, interactivas y dinámicas inherentes al proceso de aprendizaje.

Por lo que el aprendizaje y no la enseñanza, deberá ser consecuentemente la primera y más importante preocupación de los educadores y educadoras. Lo que de verdad les corresponde hacer es: promover, facilitar, crear y recrear permanentemente experiencias de aprendizaje.

Pero para que esas experiencias promuevan eficazmente el aprendizaje tienen que llenar las siguientes características, o por lo menos algunas de ellas:

- Tienen que darse en la vida, en la cotidianidad, en el proceso vital es decir, tienen que ser vivencias, sucesos, hechos, relatos que logren implicar todos los sentidos, cuantos más mejor; en una dimensión plurisensorial. Sólo así promoverán la búsqueda de sentido, de interés, adhesión, implicación, arrastre, relación empática, que conlleva la creación y recreación de nuevas relaciones con el tema de estudio, con las personas y con todos los demás elementos significativos presentes en el proceso de aprendizaje.

Esta dimensión energética, compleja y mágica llevará a los y las aprendientes a inmiscuirse, no solo en el conocimiento de la realidad estudiada, sino en su transformación.

\section{Experiencias de aprendizaje (Vivencias personales)}

Las implicaciones pedagógicas de esta nueva visión del aprender tienen que ver directamente con las experiencias de aprendizaje por cuanto por lo mismo se constituyen en los contextos pedagógicos propicios para provocar estados y propiedades emergentes.

\section{¿Cómo propiciar y promover experiencias de aprendizaje?}

Me gustaría responder a esta pregunta por medio de algunas vivencias de mi ya larga búsqueda pedagógica. Por sugerentes y por el sabor tan agradable que me dejaron, me referiré solamente a cuatro de ellas: la primera se dio en el ámbito escolar; la segunda se refiere a la educación de 
personas adultas en una población rural; la tercera se llevó a cabo en un centro superior de enseñanza, investigación y producción agroecológica; y la cuarta se dio en Guatemala en unos cursos de capacitación docente que con Daniel Prieto impartimos en las Universidades San Carlos y Rafael Landívar.

\section{Primera Vivencia}

\section{Lilia Mesa Vidal: El relato}

Hace ya muchos años conocimos a Lilia Mesa Vidal, maestra de una humilde escuela, en una barriada popular de Lima, quien a través de relatos logró crear en la escuela un entorno propicio para la vivencia de experiencias de aprendizaje.

Así lo escribió ella misma:

"Los niños necesitan que los escuchemos y nosotros les hemos convertido en oyentes obligados ¡Presten atención! ¡Silencio, cállense! Son las palabras que continuamente están oyendo.

Hacemos que se callen para empezar a invadir su mundo con frases y contenidos que ellos se ven obligados a aceptar. Los alumnos en la escuela luchan contra esta invasión forzada, se revelan y sus formas de protesta son rayar las paredes, pintarrajear las carpetas, romper continuamente las hojas de los cuadernos; en una palabra tomarse "difíciles". En mayo del año pasado me hice cargo de 32 chiquillos de primer año, "enlatados” en una pieza de $2 \mathrm{X} 2 \mathrm{mts}$. La escuela está en uno de los distritos más populosos de Lima. Estaba asustada, nunca había visto algo parecido. La atmósfera del aula era la mismísima antesala del infierno. Niños envueltos en odio, se pegaban, se subían sobre las carpetas. No había manera de hacerlos calmar, y cuando los separaba, cruzaban frases como estas: "a la hora de salida te voy a marcar”, etc.

Frente a este cuadro tan angustioso, hice a un lado el Plan y Programas que tenía para el Trimestre, y tomé la decisión de escuchar a estos niños.

Uno a uno los fui invitando para que ocuparan mi lugar, y desde allí hablaran lo que quisieran. Fue el comienzo de una de mis experiencias de aprendizaje más apasionantes; aprender que detrás de esas caritas pálidas y de aire tan agresivo había todo un mundo de florcillas y espinitas que muchas veces lastimaban dolorosamente.

Sus primeros relatos no fuero nada fáciles, vacilaban tenía dificultad para comunicar sus vivencias; por otra parte, giraban en torno a los problemas que les ocasionaban más angustias.

Un día les dije: “estoy cansada de relatos tristes, quiero relatos ale- 
gres, por favor piensen en relatos alegres”. Un niño levantó la mano y dijo: "yo sé de un relato alegre" -ven, haz tu relato en voz bien alta- "estoy bien alegre desde que usted vino señorita”. -ese fue para mí una confirmación, lo que hacía no estaba mal, sólo que de allí en adelante tenía que orientarlos hacia los aspectos más alegres de la vida. Los tenía que vivenciar positivamente, les hacía escuchar música grabada, pintábamos poesías, observábamos colores, formas contrastes, cantaban canciones que ellos escogían. Algo que ayudó enormemente en la etapa del cultivo del lenguaje oral, fue el teatro que implanté como actividad programada durante tres horas a la semana. Repetían diálogos de obras escritas para ellos. Un día, cuando menos lo pensaba, uno de ellos me dijo: "vamos a hacer una chismoseada", nombre que le han puesto a las piezas cómicas que ellos inventan. Y salieron por grupos a representar sus creaciones. ¡Fue algo sensacional!

\section{Segunda Vivencia}

\section{Jorge y Guadalupe: núcleo generador}

Praxedis Guerrero es un pueblito que se encuentra a quince minutos de la ciudad capital del Estado de Durango en México. Dividido por los desbordamientos del río Bayacora y por rencillas seculares, el pueblo presenta dos núcleos confrontados entre sí. Tanto en Praxedis de Abajo, como Praxedis de arriba, en su mayoría los habitantes se dedican a la agricultura (maíz, frijoles, sorgo). Algunos sacan arena, graba y piedra de las riberas del río. En este pueblito casi insignificante y desconocido, Jorge y Guadalupe iniciaron en el año 1987 un proyecto de educación comunitaria como consecuencia de unos cursos de pedagogía de la comunicación que impartimos en la ciudad de Durango.

Comenzaron el proyecto haciendo del pueblito un núcleo generador como la experiencia de aprendizaje concebida dentro de tres dimensiones:

1. Proceso productivo: recuperando las tierras abandonadas por la mucha emigración a Estados Unidos, con el propósito de hacerlas pro-

\section{Núcleo Generador}

La pedagogía de la comunicación se propone como objetivo básico que el educando sea capaz de crear sus propios significantes. No es tanto el de comprender los significados ajenos, cuanto el de crear sus propios sig-nificantes. El aprendiente debe pasar de receptor de información (mensajes) a creador de su propio conocimiento por la autoorganización de la información. Por eso desde el comienzo hablamos de ideogenomatesis1, y de cómo el núcleo generador meto-dológicamente es el camino de la expresión creadora. En la gestión del núcleo juega un papel primordial el estudio situacional que permite al grupo una visión de “aquí y ahora” como base para orientar el proceso de aprendizaje.

El núcleo es tanto más valido cuanto mejor sirva para:

- generar proceso

- problematizar a los aprendien-tes

- reflejar la realidad que se quiere estudiar.

En este aspecto resultan de gran importancia los contenidos del núcleo que el grupo deberá seleccionar entre las temáticas a estudiar para promover el proceso.

El núcleo se elabora con los medios o las formas de expresión que el grupo seleccione (teatro, escritos, conferencias, trabajos, etc.). 
ducir, en parte para cubrir necesidades de subsistencia alimentaria y en parte para equilibrar la economía familiar. Otro aspecto del proceso productivo fue llevar al mercado productos elaborados a nivel casero: compotas, dulces, artesanías...

2. Proceso educativo: hacer del proceso productivo una convivencia comunitaria gozosa y placentera. Un aspecto esencial fue la utilización del tiempo libre (la mayor parte del día y parte de la noche) en juegos y actividades de carácter recreativo, gozoso y placentero en vistas a una vida comunitaria agradable y gozosa para lo cual se promovieron interrelaciones personales, grupales, familiares y comunitarias dinamizadoras de gozo, de bienestar, vitalidad y aceptación benévola de los otros y otras. Para llenar este objetivo se creó en el pueblo un entorno lúdico no sólo físicamente sino por la recuperación de costumbres y fiestas con especial énfasis en los lazos de amistad y complacencia.

\section{Proceso organizativo: en} este aspecto de la experiencia, Jorge y Guadalupe, nunca fueron ajenos a la población. Compraron una casita abandonada. Estaban claros que la educación comunitaria exigía la autoorganización que los llevara a todos y todas, y en especial a ellos a una integración total a la experiencia de aprendizaje para el mejoramiento de la calidad de vida de la comunidad, que muy pronto tomó formas concretas de autoorganización de la comunidad. Para la autosatisfacción alimentaria y la convivencia más agradable, satisfactoria y significativa.

Jorge y Guadalupe concibieron el proceso como una actividad permanente. No se iniciaron con talleres y seminarios sino viviendo un proceso lo más intenso y familiar posible.

Con esto hicieron hincapié en el cambio de actitudes y en la recreación, desde la práctica, de nuevos comportamientos y en consecuencia de nuevos valores comunitarios no tanto por la prédica ideológica sino con formas cotidianas de "aprender haciendo" o mejor, "aprender produciendo". No se buscó el "sálvese quien pueda", sino tratemos de salvarnos to-

\section{Núcleo Generador}

Elaborado el núcleo sigue su lanzamiento y estudio por medio de las tres lecturas: - Connotativa (subjetiva)

- Denotativa (objetiva)

- Estructural (causas, razones, consecuencias)

Para estudiar el núcleo generador existe abundante literatura publicada en la etapa del Lenguaje Total. Para este comentario nos hemos inspirado en el Libro "Nuevas experiencias pedagógicas en América Central (Cedal, Costa Rica, 1975).

1. Idiogenomatesis. Se define como el aprendizaje concebido como un irse haciendo el ser humano por su propia iniciativa, como el propio generarse observando y leyendo los aconteceres de la capacidad de comprender y aprender. Los elementos que integran este vocablo son:

Idio: del griego propio, personal, peculiar.

Geno: del griego nacer originarse, llegar a ser.

Matesis: lo recogen los diccionarios etimológicamente con la denotación de ciencia del aprendizaje. La conjunción de estos elementos tendríamos que el vocablo significa: "un personal irse haciendo desde el conocimiento, resultado de la autoorganización de información. 
dos en forma solidaria por la organización comunitaria. El camino no fue fácil. Todo proceso educativo es largo y laborioso. Hay que volver a empezar cada día. Es ese recomenzar cada día el que permite encontrar las formas comunitarias de crecimiento y desarrollo propias de cada ambiente y de cada programa.

\section{Tercera vivencia}

\section{CATIE: Experiencias de aprendizaje}

(Talleres de capacitación pedagógica en el CATIE, Turrialba, Costa Rica 2000)

\section{A) Motivación}

Partimos de una necesidad sentida por la mayoría de los y las docentes; la obligación que tiene todo profesor o profesora, depositario de conocimientos especializados, de transmitirlos a los estudiantes.

Se trata de un quehacer que no siempre resulta fácil por las más variadas circunstancias institucionales, personales, sociales, etc. Sabemos que los procesos de enseñanza tienen que ser atractivos, motivadores y científicos para que desarrollen en los estudiantes un deseo y una actitud de aprendizaje.

El simple saber no garantiza necesariamente el saber comunicar los conocimientos. La enseñanza es un arte que requiere un aprendizaje específico. En estos talleres se ofrecen algunos elementos claves para mejorar el quehacer cotidiano de los docentes desde la revisión crítica de la propia experiencia. El cómo promover actitudes positivas de los y las estudiantes dependen en gran medida del cómo sepamos y queramos activar nuestras propias actitudes de comunicadores, motivadores, promotores y mediadores de los procesos de aprendizaje. Precisamente los talleres están centrados en la Mediación Pedagógica que desde postulados y prácticas específicas busca motivar y hacer posible en el estudiantado el acto educativo por un aprendizaje querido, productivo y significativo para ellos.

B) Objetivos

1. Redimensionar el aprendizaje a partir de una crítica a nuestras prácticas docentes

2. Organizar la enseñanza en experiencias de aprendizaje

3. Transformar la práctica docente

C) Premisa de Entrada

No toda persona que sabe, sabe enseñar.

No toda persona que cree saber enseñar, educa. 


\section{D) Desarrollo del Proceso}

Iniciamos el primero de los siete talleres con un ejercicio de Auto evaluación que posibilitó hacer del proceso una experiencia de aprendizaje.

Mantenemos en esta reseña las mismas preguntas que hicimos al personal del CATIE, persuadidos de que con algunos pequeños ajustes pueden servir para éste y otros procesos de capacitación.

\section{Cuarta vivencia}

\section{Texto paralelo}

A solicitud de los profesores de la Universidad de San Carlos de Guatemala (EDUSAC) y del programa de fortalecimiento académico de la Universidad Rafael Landívar, Radio Nederland financió un proyecto para la capacitación docente, que poco después con Daniel Prieto desarrollamos en ambas universidades.

Los resultados más tangibles de ese proyecto fueron la Mediación Pedagógica y el Texto Paralelo, por el que se busca que quienes se involucren en un proceso de aprendizaje construyan un texto como producto de sus reflexiones, experiencias, investigaciones y trabajos con el contexto. Para un mayor conocimiento del texto paralelo, puede consultarse el libro "El texto Paralelo" una propuesta metodológica para la educación y el aprendizaje” por Francisco Gutiérrez y Edith Ríos de Maldonado, publicado por el Instituto de Investigaciones y mejoramiento educativo de la Universidad San Carlos de Guatemala 1994.

\section{El texto Paralelo en el Aprendizaje}

El texto paralelo como instrumento orientador para elaborar teoría y accionar en la práctica, permite reflexionar para la construcción del conocimiento. El texto paralelo integra la teoría y la práctica hacia un acto crítico, realista y racional.

El texto paralelo, viene a constituirse en el texto libre del cual Celestin Freinet hizo uso allá pro los años 20 en St. Paul Francia. En ese entonces, Freinet se empeñaba por hacer de la pedagogía una disciplina social, crítica y problemática. Con este texto libre y sus formas de abordar la educación, Freinet crea el método natural y el método del sentido común. Con esa metodología integra experiencias, intereses y sentimientos a través de la narración y la discusión luego por la necesidad de dejarlas plasmadas e imprimirlas.

Tal como vivenció Freinet los textos libres, los textos paralelos renuevan radicalmente el hecho educativo, se orienta al participante a activar su lenguaje, su redacción y su ortografía; desarrolla la creatividad, la narración y discurso escrito. Así mismo, la actividad que propicia el texto para- 
lelo permite a los sujetos ser partícipes de la realidad social, cultural y política, toda vez que el conocimiento lo adquiere desde su contexto y lo relaciona con su práctica.

El texto paralelo puede ser un buen medio para aprender a hacer preguntas, lo cual es más importante que dar respuestas, ya que, incluye técnicas que la Escala Nueva considera, es de allí que toma en cuenta los aspectos volitivos de la persona como son la motivación y el interés, respetando la individualidad para el trabajo, sea este manual, intelectual o social.

El texto paralelo, no debe verse únicamente como una actividad manual, creemos que es mucho más que eso, es el interlocutor presente en todo momento que acepta el interrogatorio, la narración, el cuestionamiento, la búsqueda de la información y un sin fin de técnicas pedagógicas que conducen al descanso y a la relajación, desarrollando procesos mentales que van de la mano al cerebro, de lo concreto a lo abstracto, de la práctica a la teoría y viceversa.

La vivencia de Lilia Mesa, de Jorge y Guadalupe, del CATIE, y en especial la de Radio Nederland, tienen como elemento común ver la educación desde la complejidad de los seres vivos. 


\section{Bibliografía}

Assmann, Hugo (1998), Reencantar a educaçao: rumo a sociedade aprendente, Vozes, Brasil.

Idem (2002), Placer y ternura en la educación: hacia una sociedad aprendiente, Ed. Nancea, Madrid.

Idem (2005), Curiosidad y placer de aprender: el papel de la curiosidad en el aprendizaje creativo, Ed. PPC, Madrid.

Boff, Leonardo (1998), “Introducción” en Assmann, Hugo, Reencantar a educaçao: rumo a sociedade aprendente, Vozes, Brasil.

Gutiérrez, Francisco (1993), Pedagogía de la comunicación en educación popular, Ed. Popular OEI, Madrid.

Hinkelamert, Franz y Mora, Henry (2005), Economía para la vida, Ed. DEI, Costa Rica.

Swimme, Brian. El universo es un dragón verde, Ed. Sello Azul.

Varela, Francisco (2000), El fenómeno de la vida, Ed. Dolmen, Santiago de Chile. 